\title{
Inequality and mobility
}

John Hassler · José V. Rodríguez Mora · Joseph Zeira

Published online: 23 August 2007

(C) Springer Science+Business Media, LLC 2007

\begin{abstract}
Acknowledging that wage inequality and intergenerational mobility are strongly interrelated, this paper presents a model in which both are jointly determined. The model enables us to study how inequality and mobility are affected by exogenous changes and what determines their correlation. A main implication of the model is that differences in the amount of public subsidies to education and educational quality produce cross-country patterns with a negative correlation between inequality and mobility. Differences in the labor market, like differences in skill-biased technology or wage compression instead produce a positive correlation. The predictions of the model are found to be consistent with various empirical observations on mobility and inequality.
\end{abstract}

Keywords Intergenerational mobility $\cdot$ Inequality $\cdot$ Educational policy

\footnotetext{
J. Hassler $(\varangle)$

Institute for International Economics Studies (IIES), Stockholm University, Stockholm, Sweden e-mail: John@hassler.se
}

J. Hassler · J. V. Rodríguez Mora · J. Zeira

Centre for Economic Policy Research, 53-56 Great Sutton Street, London, EC1V 0DG, UK

J. V. Rodríguez Mora

University of Southampton, Southampton, UK

e-mail: sevimora@gmail.com

\section{J. V. Rodríguez Mora}

Universitat Pompeu Fabra, Barcelona, Spain

J. V. Rodríguez Mora

University of Edinburgh, Edinburgh, UK

J. Zeira

Hebrew University of Jerusalem, Jerusalem, Israel 


\section{Introduction}

Macroeconomic research on income inequality has expanded significantly in recent years. This interest in the distribution of income reflects both its social importance and also a growing awareness among economists of its significant macroeconomic implications. In this paper we claim that inequality, in particular wage inequality, should be analyzed jointly with intergenerational mobility, since the two are strongly related. On the one hand inequality affects mobility. A greater skill premium increases incentives for education acquisition and thus raises upward mobility and reduces downward mobility. On the other hand, intergenerational mobility affects the supplies of skilled and unskilled and thus the returns to skill and wage inequality. This paper studies the general equilibrium determination of both.

The joint analysis of inequality and mobility is also important for a welfare analysis. The utility of an individual depends on her current income, but also on the chances of herself or her children to change income in the future. Indirectly, individuals therefore care about future rates of social mobility since high mobility means that a shock to the income of a dynasty is less persistent. In order to capture this, the model assumes that parents derive utility from the utility of their children. This enables the model to analyze how various policies affect welfare through both inequality and mobility.

Finally and perhaps most importantly, our joint analysis of inequality and mobility can help in understanding various empirical findings. Our model predicts that differences in labor markets across countries lead to a positive correlation between inequality and mobility. If countries with high inequality also have high mobility, our model predicts that the main driving force behind these differences is to be found at the labor market, e.g., different skill-bias in their industries or different labor market institutions. If instead a negative correlation is found, the main difference is in the education system, e.g., the quality and general availability of public education. Thus, our model can contribute to understanding the underlying reasons for differences across countries in inequality and mobility.

Let us now describe the main ingredients of our model. Workers can be either skilled or unskilled and we use the ratio between their wages as a measure of inequality. This measure is endogenously determined in general equilibrium as a function of the relative supplies of skilled and unskilled. Skill is acquired through education. We assume that parents cannot borrow against the future income of their children and hence must finance education from their income only. The amount of education needed to become skilled differs both by the child's innate ability and by the parent's education. The ability of an individual is stochastic and is independent of parental ability. However, we assume that skilled parents have an advantage over unskilled parents in providing education for their children. For example, skilled parents have better knowledge of what books to buy, which tutors to hire, or may provide a home environment more suitable for education. As a result, success in education depends not only on ability but also on income of parents as well as on their education.

We assume that parents know the educational ability of their children. They allocate income between their own consumption and their child's education and that determines an ability threshold above which children become skilled. These thresholds define the probabilities of becoming skilled and unskilled for children of various backgrounds. The probabilities describe intergenerational mobility in our model. The main variable we focus on is the probability of a child of unskilled to become skilled, which is the rate of upward mobility. We use it as our main measure of mobility.

The equilibrium is analyzed by looking at two relationships between inequality and mobility. The first describes how inequality affects the investment in education and thus the rate of upward mobility. We identify two potential and opposite effects here. On the one hand, 
higher inequality increases the gains from education. This strengthens the incentive to invest in education and increases upward mobility. We call this the incentive effect. On the other hand, higher inequality reduces the ability of unskilled parents to pay for education costs that are indexed to skilled wage, like teachers' salaries. We call this negative effect of inequality on mobility the distance effect. Note that even if all educational costs are indexed to unskilled wage, like foregone income, higher inequality still reduces the relative ability of unskilled to pay for education. Namely, the difference in educational attainment between children with different social backgrounds might increase with inequality.

The second equilibrium relationship reflects the effect of mobility on inequality through the production sector and the labor market. Higher mobility increases the net flow from unskilled to skilled and reduces the number of unskilled in the long run. This raises their wage, so it reduces inequality. Hence, this creates a negative relationship between mobility and inequality.

The interaction of these two relationships determines the equilibrium. We then look at the effect of various exogenous changes and divide them to two types: changes in the production sector and changes in the education sector. Changes in the production sector tend to shift inequality and mobility in the same direction. Intuitively, such changes affect the returns to factors of production and thus affect inequality. Increased inequality tends to raise mobility through the incentive effect and hence the correlation is positive. Changes in the education sector usually lead to a negative correlation between inequality and mobility. Such changes increase access to education and thus increase mobility. That reduces the number of unskilled workers, which reduces inequality. Hence, the two variables are negatively related under such changes.

The paper then focuses on a public education, which is modeled as a subsidy to education. Similar to other improvements in education, a public subsidy reduces inequality and increases upward mobility. As in Fernandez and Rogerson (1995), skilled parents have an advantage in capturing the subsidy since they, on average, educate their children more. The direct effect of subsidies is therefore to increase the difference between educational attainment of children of skilled and of unskilled. However, in addition to previous literature, we also consider the general equilibrium effect of the subsidy on wage inequality, through the increase in supply of skill. The lower wage inequality reduces the difference in education attainment between the two classes. Furthermore, we show that the indirect effect may very well dominate the direct one and the long-run result of public education is a reduction of the difference in education attainment between children of skilled and of unskilled, unlike previous results in the literature.

Although measuring intergenerational mobility is hard, due to data limitations, empirical research in the area has been growing recently, as more longitudinal data is being accumulated. We use this research to examine whether the predictions of our model are supported by the data and we find significant support to it. Checchi et al. (1999) find that Italy is more equal but less mobile than the US. Indeed, the fact that Italy has labor market policies which significantly compress wages relative to the US, fits this positive correlation between inequality and mobility according to our model. Björklund et al. (2002) and Blanden et al. (2005) find that Nordic countries and Canada are more equal and more mobile than the US and UK. Indeed, we show that public education is much larger in these countries than in US and UK, which should lead according to our model to a negative correlation between inequality and mobility. Dahan and Gaviria (2003) find that Latin American countries are both less equal and less mobile than the US. According to our model this hints at higher public education in the US, which is found to be the case. We discuss other empirical findings as well and they are largely in line with the predictions of our model. 
This paper contributes to a growing literature that brings inequality and mobility into macroeconomics. This literature has been spurred by the recent widening of wage gaps, and by recent findings that income distribution matters for the overall economy. This point has been made both theoretically, by Loury (1981), Galor and Zeira (1993), Banerjee and Newman (1993), Aghion and Bolton (1997), and others, and empirically by Alesina and Rodrik (1994), Persson and Tabellini (1994), Perotti (1996) and Barro (2000). Intergenerational mobility has recently been studied by Galor and Tsiddon (1997), Owen and Weil (1998), Fernandez and Rogerson (1998), Maoz and Moav (1999), Hassler and Rodríguez Mora (2000), Benabou (2001) and Solon (2004). These studies focus mainly on the dynamics of inequality and mobility and their relation to economic growth. Recent papers, which focus on public education, are Glomm and Ravikumar (1992), Fernandez and Rogerson (1995), Benabou (2002) and Fender and Wang (2003). ${ }^{1}$

When placing our paper within this literature we wish to emphasize three important features of our model. The first is the question it raises. While most other papers discuss the evolution of inequality over time, our paper focuses on cross country differences in inequality and mobility and enables us to draw empirical implications. The second special element of this model is the feedback from labor supplies to wage inequality. Most papers on inequality and mobility study how wage levels affect skill acquisition. Few, however, allow the supplies of skilled and unskilled labor to affect wages in general equilibrium on the labor market. ${ }^{2}$ The third special ingredient is the modeling of the intertemporal link within a dynasty by assuming that parents care about their offspring's utility as in a Barro type model. Sharing formulation with the standard neoclassical macroeconomic model is an advantage in itself. More importantly, it adds new insights and results since it allows for the intuitive idea that people care about inequality and mobility both current and future. These are the three special ingredients of our model, and although each appears in some papers, the integration of all three elements into a unified theory of inequality and mobility has not been done previously. ${ }^{3}$

The paper is organized as follows. Section 2 presents the model, and Sect. 3 describes the steady state equilibrium. Section 4 studies the comparative statics of the equilibrium while Sect. 5 analyzes the effects of public subsidies to education. Section 6 is devoted to an empirical discussion and Sect. 7 summarizes. The appendix contains some proofs and an analysis of the case of no information on innate ability.

\section{The model}

Consider an economy that consists of two-period overlapping generations with no population growth. Each person has one child, and each generation is a continuum of unitary measure. Individuals are born unskilled and in the first period of life they can acquire education and become skilled.

In the second period of life individuals supply inelastically one unit of labor, earning as skilled $w_{s}$ or $w_{n}$ as unskilled. They consume and invest in the education of their child,

\footnotetext{
${ }^{1}$ Related are also two papers that deal with child labor and education policy: Baland and Robinson (2000) and Doepke and Zilibotti (2005).

2 Exceptions are Galor and Zeira (1993), Owen and Weil (1998) and Maoz and Moav (1999).

3 A cost of our approach is that we cannot analytically solve for the dynamics around the steady state. We are also aware of the discussion about whether bequest incentives arise from the offspring's utility or from the "warm glow of giving". See, e.g., Altonji, et al. (1997). However, in our model parents directly finance the education of their children, in which case it is more reasonable to use the utilitarian assumption rather than the alternative.
} 
deriving utility both from own consumption and from the expected utility of their offspring. Parental utility is:

$$
\ln c+\beta V_{\text {off }},
$$

where $c$ is own consumption, $V_{\text {off }}$ is expected utility of offspring, and $\beta \in(0,1)$ is the intergenerational discount factor.

For wage determination we turn to describe production in the economy. There is one final good in the economy, which is produced with skilled and unskilled labor:

$$
Y=F(a, N, S)
$$

where $N$ and $S$ are the inputs of unskilled and skilled labor, respectively, $F$ is a standard quasi-concave CRS production function of $N$ and $S$, and $a$ is a productivity parameter, which is assumed to affect skilled more than unskilled, as becomes clear below. Labor markets are competitive and hence wages are equal to their respective marginal productivities. The skilled wages is $w_{s}=F_{S}(a, N, S)=F_{S}(a, n, 1)$, where $n \equiv N / S$ is the relative supply of unskilled workers. Similarly the unskilled wages is $w_{n}=F_{N}(a, n, 1)$. Hence, the ratio of skilled to unskilled wages, which is our measure of wage inequality and is denoted I, satisfies:

$$
I \equiv \frac{w_{s}}{w_{n}}=\frac{F_{S}(a, n, 1)}{F_{N}(a, n, 1)}=I(a, n) .
$$

Due to quasi-concavity and CRS of the production function $I$ is an increasing function of $n$. We can therefore write the inverse relation, namely how the labor supplies fit the equilibrium wage inequality, in the following way:

$$
n=n(I, a) .
$$

We also assume that the range of $I$ includes levels of inequality both above and below unity, or formally, that $\lim _{n \rightarrow 0} I(a, n)<1$ and $\lim _{n \rightarrow \infty} I(a, n)>1$ for all relevant $a^{\prime} s$.

As stated above, the productivity parameter $a$ is assumed to be skill-biased. We formally assume that the elasticity of $F_{S}$ with respect to $a$ is larger than the elasticity of $F_{N}$ with respect to $a$. This therefore means that $I_{a}>0$, and also $n_{a}<0$.

In most of the analysis in this paper, we use a CES specification of the production function

$$
Y=\left(N^{\frac{\sigma-1}{\sigma}}+a^{\frac{1}{\sigma}} S^{\frac{\sigma-1}{\sigma}}\right)^{\frac{\sigma}{\sigma-1}}
$$

where $\sigma$ is the elasticity of substitution between skilled and non-skilled labor. In this case wage inequality is described by the following function:

$$
I=(a n)^{\frac{1}{\sigma}} \text {. }
$$

We next describe education acquisition. Children differ in the amount of education they need to become skilled, both due to different innate abilities to learn and to differences in parental education. The (inverse) measure of innate ability is "inaptitude." It is the amount of education a child needs to become skilled if born to a skilled parent. We denote inaptitude by $e$ and assume that it is random, independent across families and over time, and distributed uniformly on $[0,1]$. As we assume that educated parents help their children in non-pecuniary ways in addition to paying for education, children of unskilled parents face an educational barrier relative to children of skilled parents. A child with inaptitude $e$ of an unskilled parent needs $b e$ units of education to become skilled, where $b \geq 1$. The barrier $b$ reflects many factors, social, cultural, and even technological. 
The cost of one unit of education is assumed to be proportional to the unskilled wage, namely it is $\frac{w_{n}}{h}$, where $h$ parameterizes the productivity of the educational sector. This assumption is a short-cut for a more detailed description of the educational production process, where a significant part of the cost is the opportunity cost of student time, which is proportional to the unskilled wage. We believe this assumption provides a reasonable base line despite the fact that, literally, we do not have an opportunity cost of education in our model. However, we have analyzed the case where education costs are indexed to skilled wages, finding similar results, except for very high inequality levels. We return to these issues below.

Capital markets are imperfect. We assume that neither the parent nor the child can borrow to finance education and that dynasties can not accumulate wealth in order to finance education. ${ }^{4}$ As a result, parents pay for education out of their income. We assume first that education is a private good, and introduce public education in Sect. 5. Regarding the information structure of the model, we assume that the education decision is made after the child's inaptitude is revealed. Then the parent decides whether or not to spend the amount on education required to make the child skilled. In Appendix 2 we consider the case when the educational decision is taken before information on inaptitude is revealed. In this case an interesting bargaining situation emerges between parent and offspring, and as a result, intrafamily relations have an effect on inequality and mobility.

\section{Equilibrium}

The decision to invest in the child's education depends on the cost of education on the one hand and on the expected gains from education for the child on the other hand. Note that the inaptitude of the child is already known, so the expectation of gains refers to the yet unknown inaptitude of the grandchild and other future descendants. These gains depend of course on future wages for skilled and unskilled. To simplify the analysis we focus in the paper on the steady state. Hence the expected utilities of skilled and unskilled are not time dependent and we denote them by $V_{s}$ and $V_{n}$, respectively, noting that these values are calculated before the aptitude of the child is revealed.

Suppose a parent with wage $w$ has a child for whom it costs $x$ to become educated. The parent can decide to pay $x$ and have a skilled offspring or to abstain and keep the offspring unskilled. ${ }^{5}$ Education is chosen if

$$
\ln (w-x)+\beta V_{s} \geq \ln w+\beta V_{n} .
$$

Subtracting $\ln (w)$ from both sides we can derive a maximum share of the wage that a parent would pay to make her child skilled. We denote this maximum by $m$ and note that it is determined by

\footnotetext{
${ }^{4}$ There can be many reasons for the existence of the borrowing constraint. The main one is the inability to define property rights, namely to commit the offspring to return loans taken by the parents. In fact, a perfect market in our model would require that a person must be able to commit his descendents in any future generation. The inability to accumulate wealth is more restrictive and done to keep the analysis tractable. See also next footnote.

${ }^{5}$ Note that to keep the analysis tractable, we assume that a parent pays only to the child's education and is not allowed to leave an additional pecuniary bequest. It can be shown that this assumption is not needed and people do not leave an additional bequest if the steady state inequality satisfies: $I(1-\beta)>1 / h$, which is in line with our parameterization below.
} 


$$
-\frac{\ln (1-m)}{\beta}=V_{s}-V_{n} .
$$

Hence, the log specification of utility implies that $m$ is equal for skilled and unskilled and depends only on the expected gains from education, namely on the RHS of (3).

Given a value of $m$, wages and the cost of education, we can now calculate threshold levels of inaptitude for children of skilled and non-skilled such that if the inaptitude $e$ is below this threshold, the parent will pay for her becoming skilled. The threshold level for children of skilled is:

$$
e_{s}=h m I
$$

and similarly, the education threshold for children of unskilled is: ${ }^{6}$

$$
e_{n}=\frac{h m}{b} \text {. }
$$

The thresholds in Eqs. 4 and 5 are computed for a given level of $m$. This level will be determined by the optimal choices of parents, as implicitly given by (3). As we will see shortly, this implies that $m$ will be a monotone increasing function of $I$.

Note that given our distributional assumptions on $e$, the thresholds $e_{s}$ and $e_{n}$ are the shares of children from skilled and non-skilled homes, respectively, who become skilled. Hence, $1-e_{s}$ and $e_{n}$ are measures for downward and upward mobility, respectively. As we see, $e_{s} \geq e_{n}$ for two reasons. First, there is the direct social disadvantage if $b>1$. Second, the income difference affects the ability to pay for education. If $I>1$ and $b>1$, there is thus a double relative handicap for children of non-skilled.

We next turn to calculate the expected gains from education, $V_{s}-V_{n}$, using the above threshold levels and the common value of $m$. The expected utility of skilled, before their child's inaptitude becomes known, is

$$
V_{s}=\int_{0}^{e_{s}} \ln \left(w_{s}-e \frac{w_{n}}{h}\right) d e+\int_{e_{s}}^{1} \ln w_{s} d e+\beta V_{n}+e_{s} \beta\left(V_{s}-V_{n}\right) .
$$

The last term represents the expected additional utility a skilled person gets from the possibility that her child will become skilled. Calculating $V_{n}$ in the same way and taking the difference yields

$$
V_{s}-V_{n}=\frac{\ln I+\int_{0}^{e_{s}} \ln \left(1-\frac{e}{I h}\right) d e-\int_{0}^{e_{n}} \ln \left(1-e \frac{b}{h}\right) d e}{1-\beta\left(e_{s}-e_{n}\right)} .
$$

As seen from this equation the gains from education include a direct income effect, as education raises income of the child, and an indirect effect, as an educated child will be able to provide more education to her child, by avoiding the educational barrier.

Using the common value of $m$ and evaluating the integrals, ${ }^{7}$ we can express the gains from education as

$$
V_{s}-V_{n}=\frac{\ln I+h\left(I-\frac{1}{b}\right)(-(1-m) \ln (1-m)-m)}{1-\beta h\left(I-\frac{1}{b}\right) m} .
$$

When $m=0$, the gains from education are equal to $\ln I$. As $m$ rises and parents invest more in education, the gains from education may rise or decline.

\footnotetext{
6 If $h m I \geq 1$, then $e_{s}=1$ in a corner solution and all children of skilled become skilled themselves. As shown later this is impossible in the steady state.

7 Note that $\int_{0}^{e_{s}} \ln \left(1-\frac{e}{I h}\right) d e=-\left(I h-e_{S}\right) \ln \left(1-\frac{e_{s}}{I h}\right)-e_{s}$.
} 
Fig. 1 Incentive and gain from education for given wage inequality

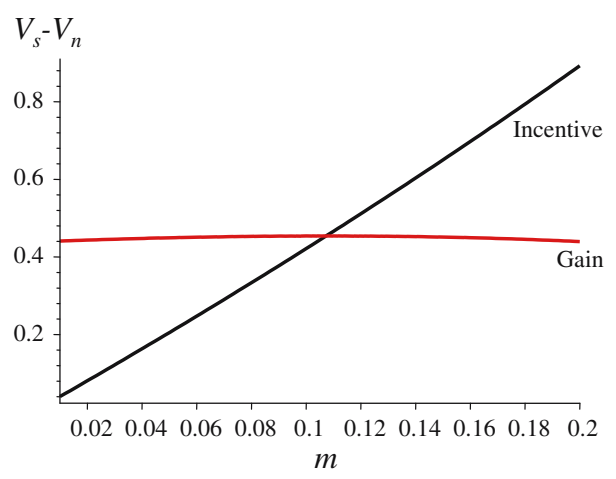

Equations 3 and 7 describe two relationships between the gains to education and $m$. Equation 3 describes how $m$ depends on the gains from education and is drawn in Fig. 1 as the monotonically upward sloping Incentive curve. Equation 7 describes, instead, how the gains from education depend on maximum educational spending $m$, and is drawn in Fig. 1 as the Gain curve. The intersection of the two curves determines the steady state level of maximum spending on education $m$. Note that the denominator of the RHS of (7) is strictly positive since $\beta h\left(I-\frac{1}{b}\right) m=\beta\left(e_{s}-e_{n}\right)<1$. In Fig. 1 we draw the two curves for the values $I=1.55, h=4, b=1.1, \beta=\frac{1}{4}$. In this example $m$ is 0.107 and consequently, $e_{s}=0.663$ and $e_{n}=0.389$.

The intersection of the incentive curve and the gain curve in Fig. 1 can be analytically characterized by the following equation, which is derived from equating the LHS of (3) and the RHS of (7):

$$
-\frac{\ln (1-m)}{\beta}=\ln I+h\left(I-\frac{1}{b}\right)(-\ln (1-m)-m) .
$$

This equation, which implicitly describes how the maximum investment in education depends on inequality, is analyzed in the following Proposition.

Proposition 1 For a given I, let $m(I)$ denote a solution to (8) such that $e_{s} \in[0,1]$. It can then be established that:

1. $m(I)$ exists for a non-degenerate domain $I \in\left[1, I_{\max }\right]$.

2. $m(I)$ is unique.

3. $m(I)$ is continuous and strictly increasing with $m(1)=0$.

\section{Proof in Appendix 1.}

According to Proposition 1 the maximum steady state spending on education $m$ depends positively on inequality $I$. Hence, upward mobility, which is:

$$
e_{n}=M(I) \equiv \frac{h}{b} m(I)
$$

also depends positively on inequality. This is the incentive effect. It reflects how higher inequality increases the gains from education, increases the maximum spending on education and thus increases upward mobility. Note also that inequality reduces downward mobility, since $1-e_{s}=1-h m(I) I$.

Clearly, income inequality and mobility are also related in the reverse direction, through the labor market. Mobility changes the supplies of skilled and unskilled, their wages and as 
Fig. 2 Steady state equilibrium, $e_{n}=L(I)$ and $e_{n}=M(I)$

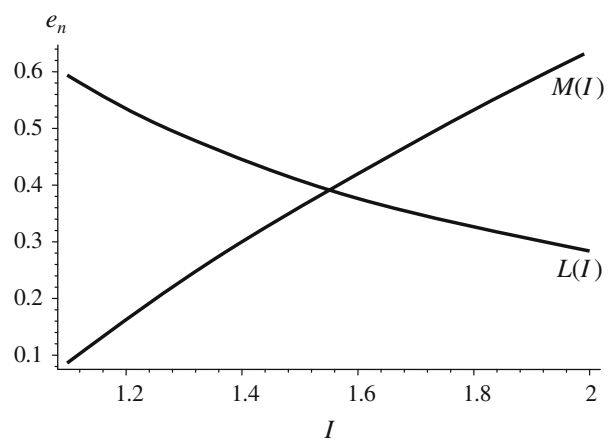

a result wage inequality. To analyze it we focus on the steady state, in which the upward flow of children of unskilled, who acquire education, must equal the downward flow of children of skilled, who do not get education. The steady state must satisfy:

$$
e_{n} N=\left(1-e_{S}\right) S \text {. }
$$

We next show that our assumptions imply that the upward and downward flows in the steady state are strictly positive. First note that $e_{s}<1$. Otherwise, by (9) either $N=0$ or $e_{n}=0$. In the first case, $n=0$ and since we have assumed $\lim _{n \rightarrow 0} I(a, n)<1$, this is inconsistent with $e_{s}=1$ since no one should become skilled when $I \leq 1$. Alternatively, if $e_{n}=0$, it follows from (4) and (5) that $e_{s}=0$ as well, contradicting the initial assumption $e_{s}=1$. Similarly, $e_{n}=e_{s}=0$ cannot be a steady state equilibrium, since then (9) implies that $S=0$, and since $\lim _{n \rightarrow \infty} I(a, n)>1$ this is inconsistent with no parent choosing to make her child skilled. We therefore conclude that the steady state must satisfy $I>1$ and $0<e_{n}<e_{s}<1$.

In addition to the steady state flow restriction in (9), the relation between inequality and the ratio of non-skilled to skilled is determined at the labor market by (1). Substituting this equation, together with (4) and (5) in Eq. 9, we get the following equilibrium condition:

$$
e_{n}=\frac{1}{n(I, a)+I b} \equiv L(I) .
$$

The function $L(I)$ denotes the labor market relation between mobility and inequality, whereby mobility affects the distribution of workers and thus wage inequality. It is clear from Eq. 10 that $L(I)$ is decreasing. Intuitively, there are two reasons for that. First, higher inequality implies that the supply of skilled is smaller and the supply of unskilled is larger. Hence, for the same mobility rates the upward flow increases and the downward flow decreases. To restore equality of the two flows, so that Eq. 9 holds, upward mobility must decline and downward mobility must rise. The second reason is due to do the difference between educational attainments of children of skilled and unskilled. If inequality rises, downward mobility declines for a given level of upward mobility as the skilled can pay more for education. To restore equality of up and down flows, upward mobility must decline. Hence, these two mechanisms lead to a negative effect of inequality on upward mobility, as described by the function $L$.

Our model is now fully solved and we depict the two equilibrium conditions in Fig. 2, under the previous specifications. ${ }^{8}$ The downward sloping curve represents $e_{n}=L(I)$ and

8 The parameters used here and in the following graphs unless otherwise stated are $a=2.5, b=1.1, h=4$, and $\beta=0.25$. Following Hornstein and Krusell (2003), we set $\sigma=1.67$. 
Fig. 3 Skill-technical bias, $a$, increases from 2.5 (solid line) to 3 (dotted line)

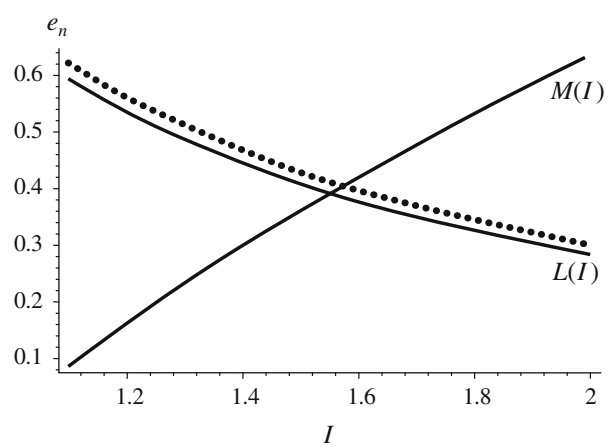

the upward sloping $e_{n}=M(I)$. At the crossing, the labor market is in a steady state equilibrium where educational decisions are taken optimally.

Proposition 2 There is a unique steady state equilibrium in the model, satisfying $e_{n}=$ $L(I)=M(I)$. The steady state wage inequality satisfies $1<I<I_{\max }$ and $e_{n}<\left(b I_{\max }\right)^{-1}$.

Proof To establish the proposition, we note that

1. $L^{\prime}<0$ and $M^{\prime}>0$,

2. $M(1)=0$ and $L(1)=\frac{1}{n(1 ; a)+b}>0$, and

3. $M\left(I_{\max }\right)=\frac{1}{I_{\max } b}>\frac{1}{n\left(I_{\max }, a\right)+I_{\max } b}=L\left(I_{\max }\right)$.

\section{Comparative statics}

This section contains a comparative statics analysis of the steady state. In general such an analysis can be interpreted in two possible ways: as explaining cross-country differences and as explaining changes within the same country over time.

\subsection{Changes in the production sector}

In this sub-section we turn to examine exogenous changes in the production sector. We first analyze the case of skill-biased-technical-change (SBTC), being a topic of much research recently. As already noted, such a change is described by a shift of the parameter $a$ in the production function. Note that such a change has no direct effect on the function relating parental educational decisions to inequality. Thus, an increase in $a$ has no effect on the $M$ curve. However, an increase in $a$ shifts the $L$ curve up and to the right. As a result, inequality $I$ increases, upward mobility increases and the maximum share of income spent on education $m$ rises as well (Fig. 3).

Another type of change, which is usually more related to differences across countries, and that has a similar effect as a negative SBTC, is wage compression. A country with much labor regulation or strong labor unions tends to have more compressed wages. In our model this can be described as having a lower $a$. Hence, such a country experiences lower wage inequality and since only the $L(I)$ curve shifts inwards, upward mobility must be lower as well. 
Fig. 4 Better education, $h$ increases from 4 (solid line) to 4.5 (dotted line)

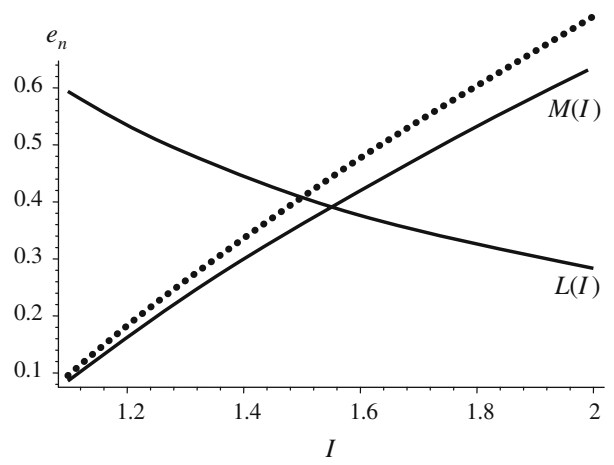

\subsection{Changes in the education sector}

In this section we turn to examine how changes in the education sector affect the steady state equilibrium levels of inequality and mobility. More specifically, we examine the effects of changes in the parameters $h$ and $b$ on the steady state equilibrium, where $h$ is the overall productivity of education, and $b$ describes the sociocultural barriers to education faced by children of unskilled parents.

Intuitively, improvements in the productivity of education should lead to higher mobility and lower inequality. Better education enables children of unskilled to acquire more education for their money, so that more of them become skilled. Hence, upward mobility increases. As better education increases the number of skilled and reduces the number of unskilled, inequality falls. However, this intuitive argument does not take into account general equilibrium effects. We therefore turn to a formal analysis of changes in $h$ and $b$.

Consider first an increase in the overall productivity of education $h$. First, for any given $m$, upward mobility, which is equal to $h \mathrm{mb}^{-1}$, increases. Second, for any given inequality $I$, maximum spending on education $m$ increases as well, because a rise in $h$ increases the gains from education. The reason for this is that part of the gains from education of a child is the higher probability of the grandchild to go to school. Since this probability increases if education is less costly, it increases the gains from education and $m$, as seen in Eq. 8 . The two effects together shift the $M$ curve upward, as shown in Fig. 4.

When education is more productive, the $L(I)$ curve remains unchanged, as seen in Eq. 10 . The intuition is simple: upward mobility and downward mobility change together when education becomes more efficient. Thus, for the same level of upward mobility the distribution of skill is unchanged and so is $I$. Hence, the economy moves along the $L(I)$ curve in Fig. 4 to the left: inequality falls and upward mobility rises. Note, that the effect on investment in education $m$ is ambiguous. Lower inequality reduces the gains from education, which mitigates the positive effect described above.

We next examine the effect of a reduction of the educational barrier to children of unskilled, $b$. The direct effect of a reduction in $b$ is to increase upward mobility. However, there are also indirect effects. Consider first the educational choice. In Eq. 8 we see that a reduction in $b$ reduces the maximum spending on education $m$. The intuitive explanation is that part of the gain from education is that an educated person has an advantage over an uneducated in providing education for her offspring, even when income is controlled for. A lower $b$ reduces this part of the gain from education. However, it can be shown that the 
indirect effect never overturns the first. ${ }^{9}$ Thus, a reduction in the educational barrier leads to an upward shift of the $M(I)$ curve. A reduction in $b$ also shifts the $L$ curve upward and to the right. Formally, this is clear from Eq. 10. Intuitively, if the social barrier $b$ is reduced, then for upward mobility $e_{n}$ to remain unchanged, the maximum investment in education $m$ must be lower. Hence, while upward mobility remains unchanged, downward mobility increases due to the reduction in $m$. This increases the supply of unskilled and increases, as a result, wage inequality $I$. This is why the $L$ curve shifts to the right. The fact that both $M$ and $L$ curves shift upward implies that mobility increases. The effect on inequality appears ambiguous from the diagrammatic analysis but the following proposition shows that at least under the CES production function the reduction in $b$ reduces inequality.

Proposition 3 Under the CES assumption Eq. 2, a reduction in the education barrier $b$ raises mobility $e_{n}$ and reduces inequality $I$.

\section{Proof in Appendix}

We can therefore summarize this section by noting that the correlation between changes in inequality and in mobility depends on the underlying causes for the changes. Changes in the production technology or the labor market lead to mobility and inequality moving in the same direction. Changes in the educational system, like changes in educational productivity or barriers faced by the unskilled, lead to mobility and inequality moving in opposite directions.

\subsection{Education costs indexed to skilled wage}

At this point, we would like to return to the assumption that educational costs are mainly opportunity costs, and thus indexed to the non-skilled wage. ${ }^{10}$

If this assumption is changed and instead the cost of education is indexed to the skilled wage, the main change is that the slope of the $M$ curve, now described by $M(I)=$ $h m(I)(b I)^{-1}$, might become negative at high levels of inequality $I$. The reason for that is that as inequality increases, it becomes increasingly costly for unskilled parents to pay for their offspring's education. Eventually, this distance effect might dominate and then the slope

9 To see this, note that

$$
\left.\frac{d e_{n}}{d b}\right|_{e_{n}=M(I)}=\frac{h}{b} \frac{m}{b}\left(\frac{d m}{d b} \frac{b}{m}-1\right)
$$

where $\frac{d m}{d b}$ is calculated under (8). Furthermore,

$$
\begin{aligned}
\frac{d m}{d b} \frac{b}{m} & =\frac{h m}{b} \frac{(1-m)(-\ln (1-m)-m)}{m^{2}\left(\frac{1}{\beta}-h\left(I-\frac{1}{b}\right) m\right)} \\
& <\frac{e_{n}}{\frac{1}{\beta}-\left(e_{S}-e_{n}\right)} \frac{(1-m)(-\ln (1-m)-m)}{m^{2}} .
\end{aligned}
$$

Finally,

$$
\frac{e_{n}}{\frac{1}{\beta}-\left(e_{s}-e_{n}\right)}=\left(1+\frac{1}{e_{n}}\left(\frac{1}{\beta}-e_{s}\right)\right)^{-1}<1
$$

and $\frac{(1-m)(-\ln (1-m)-m)}{m^{2}}$ is decreasing from $\frac{1}{2}$ in the range $m \in(0,1)$. Therefore, $\left.\frac{d e_{n}}{d b}\right|_{e_{n}=M(I)}<0$.

10 A formal analysis is available upon request. 
of the $M$ becomes negative. The conclusion, however, is that the model behaves in a fairly similar way under this alternative assumption. The main difference is that at very high levels of inequality a skill-biased technical change might lead to a reduction of mobility instead of higher mobility. But we should note that this case appears less plausible for developed economies, requiring, in particular, that the level of inequality at which the curve $M$ changes slope is smaller than $I_{\max }$.

\section{Public subsidies to education}

This section introduces public support to education. This support can be partial, so that some education costs are still privately financed. Our assumption in this section therefore differs from those in Glomm and Ravikumar (1992), where public education rules out private expenditures on education. In our model public education helps parents increase the probability of their children to become skilled by lowering the private cost of schooling. We assume that public education is financed by a proportional tax on income.

Intuitively, one may think that public education should lead to higher mobility and lower inequality. Public education enables more children of unskilled to go to school, thus raising upward mobility. It also increases the number of skilled workers and reduces the number of unskilled, thus lowering inequality. Indeed, these are usually the declared goals of increases in public education. However, the analysis should take account of other secondary effects, which might reduce these primary effects, and might even harm the declared goals. In order to assess these opposing effects we turn to a formal analysis of public subsidies to education, which helps us examine these issues within a general equilibrium framework.

Let $p$ be a proportional subsidy to education, paid by a proportional income tax $T$. To simplify calculation we assume that educational spending is tax-deductible. Hence, a parent that spends a share $m$ of gross income on education consumes $(1-T)(1-m) w$ and gets $\mathrm{hm} /(1-p)$ units of education if unskilled and $\mathrm{hmI} /(1-p)$ units of education if skilled. Consequently,

$$
\begin{aligned}
e_{n} & =\frac{m h}{b(1-p)} \\
e_{s} & =\frac{m h I}{1-p}=e_{n} b I,
\end{aligned}
$$

and, as in the case of changes in $h$, the $L(I)$ curve is unaffected by changes in $p$ and $T$.

Note that public subsidies to education benefit skilled parents by more than unskilled in the sense that $\frac{\partial e_{s}}{\partial p}>\frac{\partial e_{n}}{\partial p}$, both because they use education better, provided $b>1$, and since they have a higher income. This point has been made by Fernandez and Rogerson (1995). However, we have an additional indirect effect through wage inequality. Public education increases the supply of skill, which reduces $I$ and thus reduces the difference $e_{s}-e_{n}$. We show in a numerical example below that it is perfectly possible that the indirect effect dominates the direct effect and that despite the double handicap of unskilled parents they increase education attainment by more than skilled parents in the long-run.

To analyze the long-run effects of educational subsidies, we start by analyzing the incentives to invest in education. First, note that since the utility loss of taxes is additive, given by $\ln (1-T)$, regardless of income and the share spent on education, Eq. 3 is unaffected. ${ }^{11}$ straightforward calculation yields that (7) now becomes

11 Clearly, a progressive tax system affects educational incentives directly. 
Fig. 5 Welfare as a function of the subsidy rate $p$

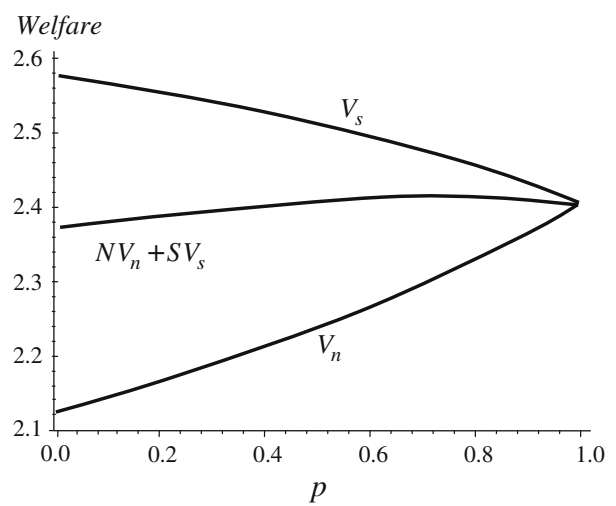

$$
V_{s}-V_{n}=\frac{\ln I+\left(I-\frac{1}{b}\right) \frac{h}{1-p}(-(1-m) \ln (1-m)-m)}{1-\beta \frac{m h}{1-p}\left(I-\frac{1}{b}\right)} .
$$

An increase in $p$ thus raises the gains from education and its effect is isomorphic to an increase in $h$, the productivity of education.

We therefore conclude that inequality falls and upward mobility rises with $p$. This result shows that the effect of public education on mobility and inequality is similar to the effects of the other changes in the educational sector, which are analyzed in Sect. 4.2.

We next briefly discuss some welfare aspects of public education. Specifically, we examine who prefers more subsidies to education, the skilled or the unskilled. On the one hand the unskilled gain more from the subsidy, since it reduces inequality by raising their wage and since it increases mobility and thus increases their children's chance to escape from poverty. On the other hand, the skilled can use the public subsidy to education better, since they face a lower barrier to education.

In Fig. 5 we plot the welfare of skilled and unskilled as measured by $V_{s}$ and $V_{n}$, respectively, against $p$. In addition, we also plot aggregate welfare, i.e., $N V_{n}+S V_{s}$. We use the same parameters as above. ${ }^{12}$

In Fig. 5 we see that $V_{s}$ is monotonically decreasing in $p$, while the opposite is true for $V_{n}$. Public education affects welfare via its effect on inequality and mobility and via the tax cost. The effect of inequality is positive for the unskilled, since their wage rises and negative for the skilled since their wage declines. The effect through mobility is positive for both, since public education reduces the chance that the child will become unskilled. In Fig. 5 we see that for the skilled, the inequality effect dominates the mobility effect and they prefer to reduce public education as much as possible. The unskilled gain from public education both through inequality and through mobility and despite the fact that they are less likely to get the subsidy since fewer of their children get educated they prefer to have as much subsidy as possible.

Figure 5 also shows that average welfare is maximized by a positive subsidy rate. The social optimal subsidy of education is $p=0.751$, which is financed by a proportional tax

12 The budget constraint of the government is $T=\frac{p\left(e_{s}^{2}+\left(1-e_{s}\right) b e_{n}\right)}{2 h(n+I)-(1-p)\left(e_{s}^{2}+\left(1-e_{s}\right) b e_{n}\right)}$. Proof and code to solve for the utility levels numerically are available upon request. 
Fig. 6 Mobility vs. inequality
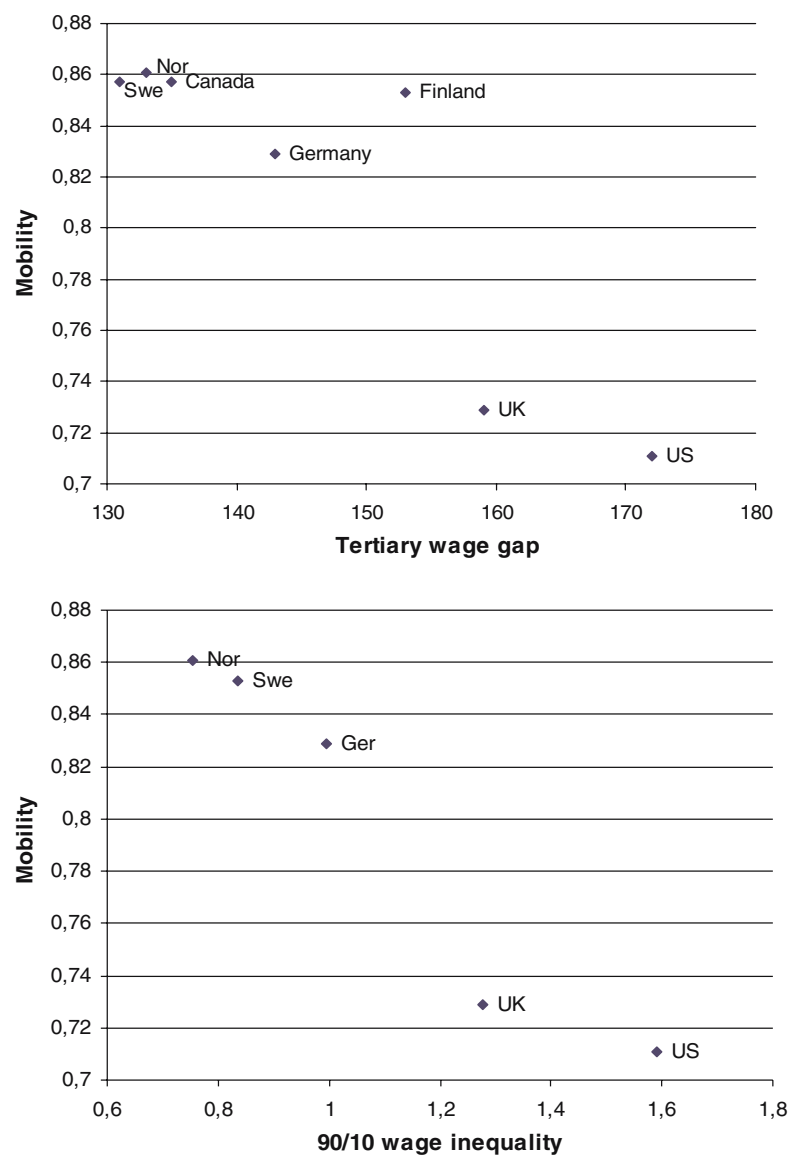

of $3.87 \%$. Interestingly these figures are not far from observed values. ${ }^{13}$ The effect of this subsidy is to increase upward mobility from $e_{n}=0.393$ to 0.557 . Also $e_{s}$ increases, but by less, from $e_{s}=0.672$ to 0.713 . Therefore, the difference in educational attainment, $e_{s}-e_{n}$ falls from 0.279 to 0.156 , i.e., it is almost cut in half. The changes in $e_{s}$ and $e_{n}$ increase the supply of skilled, causing wage inequality to fall from 1.554 to 1.165 and the wage of unskilled to increase by $21.4 \%$.

The finding that unskilled and skilled have opposing views on public subsidies remains also if the barrier to education is much higher. Setting $b=3$, for example, implies that mobility, with and without subsidies, is very low. But, nevertheless, the unskilled still prefer $100 \%$ subsidies while the skilled still prefer none. Interestingly, the welfare maximizing level of subsidies is almost the same as in the low barrier case, it is $p=0.760$. The subsidy increases $e_{n}$ from 0.170 to 0.246 and $e_{s}$ from 0.843 to 0.870 . Also in this case $e_{s}-e_{n}$ falls, now from 0.673 to 0.624 . Inequality falls from 1.649 to 1.181 and the wage of unskilled increases by $24.9 \%$.

13 The average share of public education in total education costs in OECD countries is 0.884 and the average public education costs as a share of GDP in these countries is 4.96\%. Source: OECD in Figures-2005 Edition. Table "Education expenditures". 


\section{Empirical implications}

A main message of our theoretical model is that features of the educational system tend to generate a negative association between inequality and mobility, while features of the labor market tend to generate a positive association between them. As a result we can use observations on wage inequality and intergenerational mobility in order to learn which underlying factors caused them. In this section we review some international comparisons of inequality and mobility and show that their correlations are in line with the predictions of the model. Measuring wage inequality, e.g., the ratio of skilled to unskilled wages is relatively simple, though the definition of skill might differ across countries. Measuring intergenerational mobility is more difficult due to lack of sufficient data that go back to past generations. As a result not many studies have produced internationally comparable measures. One of these few studies is Blanden et al. (2005), extending work by Björklund et al. (2002). They provide measures of mobility, based on intergenerational correlation of income between fathers and sons, for UK, Canada, Denmark, Finland, Norway, Sweden, US and West Germany. They find that Canada and the Nordic countries have relatively high degrees of mobility, Britain and the US have substantially lower mobility, while Germany is an intermediate case. In Fig. 6 we plot the reported levels of mobility, measured as 1 minus the intergenerational partial correlation coefficient, against measures of wage inequality. In the upper panel, we use the college education wage gap, taken from the "OECD Education at a glance 2002". In the lower panel, we instead use the log wage difference between the 90th and the 10th wage decile as reported by Blau and Kahn (1996). ${ }^{14}$ As we see, the general pattern here is a negative relation between inequality and mobility. This is largely driven by the difference between, on the one hand, the US and UK, with high inequality and low mobility and on the other, the northern European countries and Canada, where inequality is low and mobility is high. This pattern remains also if other measures of inequality reported in Blau and Kahn (1996) are used. For differences within the group of European countries and Canada, however, such a negative relation is not clearly visible, an observation we will return to below.

Applying our model to the correlations shown in the two graphs leads to a clear conclusion. The main difference between the US and UK and the Northern European countries and Canada lies in the area of education. Despite other possible differences like wage compression in Europe, emphasized by Blau and Kahn (1996) and further discussed below, our interpretation is that differences in the educational systems must play a more prominent role, given the observed differences in mobility and inequality. There is support in the data for this interpretation. In Canada and in the Scandinavian countries, government subsidies to higher education are substantially higher than in the US and the UK. In Table 1, we report public spending on tertiary education. The average public spending in Canada and the Scandinavian countries is almost twice as high as in the UK and the US (2.03\% vs. $1.17 \%)$ and even higher relative to the Mediterranean countries, which we will return to below. ${ }^{15}$ We also note that public expenditures on tertiary education are low in Germany, despite a fairly low level of inequality and a fairly high level of mobility, a fact less easy to explain with our model. However, the fact that the German educational system stands out by relying heavily on apprenticeships makes Germany a special case. More than half the cohort of young individuals participate in the apprenticeships system including also a substantial share of individuals that later get a tertiary education (the "double qualification strategy"), see Ryan

\footnotetext{
14 Canada and Finland are not included in the data from Blau and Kahn.

15 The Scandinavian countries and Canada also spend a larger share of GDP on education below the tertiary level, although this is arguably less relevant in the perspective of our model.
} 
Table 1 Public spending on tertiary education

Source: OECD.stat webpage (http://stats.oecd.org/wbos/)
Average share of GDP 1997-2003 (\%)

\begin{tabular}{ll}
\hline Norway & 1.96 \\
Sweden & 2.04 \\
Canada & 1.73 \\
Finland & 2.02 \\
Denmark & 2.38 \\
Germany & 1.11 \\
UK & 0.96 \\
US & 1.38 \\
Italy & 0.78 \\
Spain & 0.93 \\
Portugal & 0.98 \\
Ireland & 1.41 \\
Greece & 0.85 \\
\hline
\end{tabular}

(2001). A possible interpretation is that the German society as a whole spends a substantial amount of resources on education of high quality provided on an equal opportunity basis, despite a relatively small amount of subsidies channeled directly via the public budget.

We next turn to another group of countries, mainly from Southern Europe. Measures of mobility for these countries are scarce, but recently Comi (2003) used the European Community Household panel to derive such measures. Despite some problems with this dataset, in particular that sons' earnings are measured at a rather early age, it has the clear advantage that the data are collected in a similar way across all countries. The findings of Comi are that the Mediterranean countries, Portugal and Ireland have a relatively low degree of intergenerational mobility. Comi (2003) finds no systematic evidence that the low degree of mobility in these countries is correlated with the educational wage premia. Hence, mobility in Southern Europe is lower than in Northern Europe, while inequality is quite similar in the two regions. Such a cross-country difference is not along the diagonal in the mobility/inequality diagram and thus requires more than one difference between the two groups of countries. One of the differences between Northern and Southern Europe is that the former spend much more public resources on higher education, as seen in Table 1. By itself, this would lead to higher mobility in the north, but also lower inequality. We observe the former, but not the latter. We argue that the remaining difference is that wage compression is much more important in Southern Europe than in Northern.

Wage compression, i.e., that wages differ less than individual productivities, is obviously an impossibility when labor and product markets are perfect. However, perfect markets, particularly in Europe, is not a good description of reality. Minimum wages, collective bargaining, employment protection legislation, search frictions and legal and other entry barriers are some features of European labor and product markets that create the possibility that wages deviate from marginal productivities. Measuring cross-country differences in wage compression is not a simple task and we cannot claim that the evidence is completely conclusive. However, evidence supporting the idea that wage compression is more important in Southern than in Northern Europe does exist. Mourre (2005) uses the European Unions Structure of Earnings Survey 2002. Using a standard CES production function, it is shown that a wage 
compression coefficient can be identified by separately estimating a standard labor demand equation and an equation for the relative labor demand as a function of relative wages. The finding is that wage compression is large in EU as a whole-relative wages are compressed by between a fifth and a quarter. More importantly, while strong and significant evidence for wage compression is found for continental and Southern Europe, no significant wage compression is found for northern EU countries (Denmark, Finland, Sweden and the Netherlands) nor for the Anglo-Saxon countries (Ireland and the UK). This result is perhaps surprising given the long history of strong unions and centralized bargaining in Scandinavia. It should be noted, however, that the so called "solidaric wage policy" pursued by Scandinavian labor unions aimed at reducing horizontal rather than vertical wage differences (see e.g., Agell and Lommerud 1993). The idea was that by demanding "equal pay for equal jobs", structural change, i.e., an expansion/contraction of sectors/firms with high/low productivity, could be speeded up. To the extent that this policy was successful, it would create wage compression between individuals with similar characteristics, i.e., reduce the variance of the wage residual, rather than compressing the college premium or other measures of vertical wage inequality. Another observation, consistent with this, is that the incidence of long-term unemployment is much higher in Southern than in Northern Europe. ${ }^{16}$

These empirical findings mean that the countries in Northern Europe differ from the countries in Southern Europe in two main aspects relevant to our theory. Northern Europe has more public education than the South, and has less wage compression in the labor market. The first difference should lead to higher mobility and more equality in Northern Europe. The second difference should lead to less equality but more mobility in Northern Europe. Indeed, the data show that Northern Europe is much more mobile than Southern Europe. Since the two differences affect inequality in two opposite ways it is not surprising that in reality inequality is found to be similar in the North and the South of Europe. Hence, this relationship also fits our model fairly well.

Checchi et al. (1999) provide further empirical evidence to this conclusion. They compare mobility and inequality in Italy and in the US and find that while mobility in Italy is lower than in the US, also inequality is much lower than in the US. According to our model, the positive correlation between mobility and inequality when comparing Italy and the US, points to differences in the labor market. As discussed above, the evidence in Mourre (2005) is that wage compression is high in Southern Europe. Furthermore, comparing the US and Europe, Blau and Kahn (1996, 2002), show that labor market regulation created significant wage compression in European countries compared to the US and the UK. Blanchard and Wolfers (2000) have also shown that the higher unemployment in Europe is due to labor regulations, like generous unemployment benefits, high minimum wages, high firing costs, and more. Alesina, Glaeser and Sacerdote (2005) have shown that such labor market regulations have reduced hours worked in Europe relative to the US. More specifically, Erikson and Ichino (1994) document an "extreme compression" of wages in Italy during the 1970s.

Another international comparison of intergenerational mobility appears in Dahan and Gaviria (2001). They study 16 Latin American countries and compare them to the US. In order to overcome data limitations this paper develops an interesting measure to mobility which happens to be close in spirit to this paper. They measure it by sibling correlations of success and failure in the schooling system. Dahan and Gaviria find that within the Latin American countries and even more so relative to the US, inequality and mobility are negatively correlated. Thus, the average Gini coefficient in the Latin American countries is .51

\footnotetext{
16 The average share of unemployed with an unemployment duration over a year in the years 2000-2006 was $19 \%$ in Scandinavia, 10\% in the US, 24\% in the UK, but as large as 57\% in Italy. Source: OECD.stat webpage. (http://stats.oecd.org/wbos/).
} 
while it is .379 in the US. Mobility (1-sibling coefficient) is .505 in the Latin American countries while it is equal to .797 in the US. This negative correlation points at differences in the education system between the two regions. Indeed, comparing the public expenditures' share of GDP relative to the percentage of children in the two regions (which is a proxy for what is called $p$ in the model) we get that the public support to education in the US is much larger. This figure is .248 in the US, while it is only .109 in the 16 Latin American countries, namely higher by a factor of two and a half. Hence, higher public support to education in the US relative to Latin America comes with higher mobility and lower inequality, as the model predicts.

We conclude this section with a few observations on changes in mobility and inequality over time. Empirical comparisons of mobility over time are very rare, as mobility measurements are rather new and it is hard to find data for past generations. One exception is Lambert et al. (2007), who use a host of data sets on mobility. Most of these data sets are fairly recent, from the Post War period. But they also add a unique historical data set from the Cambridge Family History Study. This data set consists of people who traced their family history back in time over a long period of time, of more than two centuries. This is of course not a sample, but it supplies significant information on the dynamics of mobility in Britain. As mentioned above, the authors use more data sets for recent periods. The way they measure mobility is occupational, which fits the spirit of our paper well. They measure occupational correlation between father and child. The pattern the study finds, as presented in Fig. 1 in that paper, is that mobility in Britain has been on a steady but very slow and gradual rise in the last two centuries. Interestingly, since the 1970s mobility began to rise much more rapidly. This result is interesting since 1972 is an important year in the history of public education in the UK. In that year compulsory education was extended to the age of 16 from an age of 12 . Although there was a mechanism that enabled extension for bright students to secondary school since 1902, but it was not until 1972 that this extension became effective for all. The coincidence between this change and the sharp rise in mobility adds another empirical support to our model.

Another example of measuring changes in mobility over time is supplied by Güell et al. (2007), who measure intergenerational mobility in Catalonia by studying surnames. They compare people above and below the age of fifty and find that mobility in the current generation is lower than in the previous generation. Interestingly the skilled to unskilled wage ratio for the older generation were close to 2 , while for the younger generation it is 1.56 . Thus both mobility and inequality went down, pointing in the direction of changes in labor market institutions. Indeed, Spain went through a significant change thirty years ago with the death of Franco. While before his death labor unions were not allowed and labor markets were not regulated, after his death labor unions regained much importance and labor market policies became more similar to other Southern European countries. Hence, Spain went through a major increase in wage compression. The expected effect of such a change on inequality and mobility according to our model is indeed in line with the results of Güell et al. (2007).

Another phenomenon that our analysis can shed light on is the rise of wage inequality in the US in recent decades. The main explanation to this increase has been skill-biased technical change, but there have been other explanations as well. Our model claims that if this widening of the wage gap is a result of SBTC, then it should be accompanied with an increase in intergenerational mobility as well. Indeed Mayer and Lopoo (2001) find evidence in PSID data that intergenerational mobility is higher for individuals born after 1953. Thus, although a small sample size and the difficulty to measure lifetime income make this finding somewhat preliminary, it clearly supports our model's predictions. A skill biased technical change increases both inequality and mobility. 


\section{Conclusions}

This paper presents a simple theoretical model that analyzes the joint determination of income inequality, skill distribution and intergenerational mobility. Its main focus is on the expected correlation between inequality and mobility. Empirical studies have shown that this correlation across countries can be either positive or negative. Our paper gives a simple explanation to these findings. We show that the correlation between inequality and mobility is positive if the underlying differences are in the production sector, while the correlation is negative if the underlying changes are in the education sector. In the empirical section of the paper, we review results supporting the predictions of our model and we therefore believe it helps in understanding observed differences in inequality across countries, and also over time in a single country.

Our model can be used to examine additional economic, social and cultural variables. For example, the analysis of the case of missing information in the appendix shows, that countries, in which parents are more dominant within the family, tend to have less education, less mobility and higher inequality. We believe that the framework presented here can be further extended in many other interesting directions.

Finally, we have shown that public subsidies to education may be particularly beneficial for unskilled individuals. It is tempting to interpret this result as saying that unskilled voters should be expected to vote in favor of educational subsidies. However, it may be premature to draw such a conclusion. First, we analyze steady states and the inequality reducing effect of educational subsides occurs with a substantial lag since it takes time for the relative supplies of skilled and non-skilled to change after an educational reform. Second, we have analyzed the consequences of a permanent change in the subsidy rate, while political decisions may be better modeled as taken without commitment. We leave the study of the dynamic political determination of educational subsidies in a model with endogenous wage formation for future work.

Acknowledgments We thank Omer Moav and Fabrizio Zilibotti for very useful comments on previous drafts. We also thank the referees and the editor of this journal for important suggestions and criticisms. JVRM thanks the financial support of the Spanish Ministry of Science and Education (project SEJ2004-06877).

\section{Appendix}

Appendix 1: Proofs

\section{Proof of proposition 1}

We can rewrite (8) as:

$$
\left(h\left(I-\frac{1}{b}\right)-\frac{1}{\beta}\right)(-\ln (1-m))+\ln I=h\left(I-\frac{1}{b}\right) m
$$

The RHS of (A.1) is a linear increasing function of $m$ while the LHS is going from $\ln I$ to $\infty$ (or $-\infty)$ and is increasing and convex (decreasing and concave) if $h\left(I-\frac{1}{b}\right)-\frac{1}{\beta}$ is larger (smaller) than zero. Hence, there can be at most two solutions to (A.1). We show below that the smallest solution, denoted $m(I)$, is the relevant one since the larger implies $e_{s}>1$.

We begin the analysis with $I=1$. In this case $m=0$ is a solution. If $h\left(I-\frac{1}{b}\right)-\frac{1}{\beta} \leq 0$, a unique solution clearly exists for any $I \geq 1$. 
Now consider the alternative case, $h\left(I-\frac{1}{b}\right)-\frac{1}{\beta}>0$. Note that the LHS has a strictly smaller derivative with respect to $m$ at $m=0$. Therefore, continuity ensures that a solution remains for $I>1$ in a neighborhood of 1 . For a sufficiently high level of inequality no solution exists. The maximum level of inequality for which a solution exists is $I^{*}$ where the solution $m^{*}$ occurs at the tangency of the LHS and the RHS, namely at

$$
m^{*}=m\left(I^{*}\right)=\frac{1}{\beta h\left(I^{*}-\frac{1}{b}\right)} .
$$

Hence, for $I<I^{*}$, at least one solution exists, that is $m(I)$ exists in the range $I \in\left[1, I^{*}\right]$. Next, we show that the smallest solution $m(I)$ is the only solution to (A.1) such that $e_{s} \leq 1$. To see this, note that if there are two intersection points to the two sides of (A.1), then in between them, there is a point $m_{p}$, where the two curves have the same slope, given by

$$
m_{p}=\frac{1}{\beta h\left(I-\frac{1}{b}\right)},
$$

where we note that $m_{p}<1$ when $h\left(I-\frac{1}{b}\right)-\frac{1}{\beta}>0$. If there were two solutions to (A.1), then in one $m>m_{p}$. Then

$$
e_{s}=m h I>m_{p} h I=\frac{I}{\beta\left(I-\frac{1}{b}\right)} \geq 1 .
$$

We next analyze the slope of the function $m(I)$. First, note that the LHS (A.1) must cut the RHS from above at $m=m(I)$. Second, a higher $I$ raises both the LHS and the RHS of (A.1). But since $-\ln (1-m)>m$, the LHS rises by more than the RHS. Therefore, an increase in $I$ must lead to higher $m$, i.e., $m^{\prime}(I)>0$.

Finally, implicitly define $I_{\max }$ from

$$
m\left(I_{\max }\right) h I_{\max }=1,
$$

i.e., as the highest level of inequality such that $e_{s}$ is no larger than unity. To conclude the proof, we must show that $I_{\max } \leq I^{*}$. Now, at $I^{*}$, we have

$$
m\left(I^{*}\right) h I^{*}=\frac{I^{*}}{\beta\left(I^{*}-\frac{1}{b}\right)}>1 .
$$

Since $m(I) h I$ is increasing in $I, I^{*}>I_{\max }$

\section{Proof of proposition 3}

Using, the definition of $e_{s}$ and $e_{n}$, solving for $m$, and substituting in (8), yields

$$
\begin{aligned}
X \equiv & -\ln I-\left(h\left(I-\frac{1}{b}\right)-\frac{1}{\beta}\right)\left(-\ln \left(1-\frac{b}{h\left(I^{\sigma}+I b\right)}\right)\right) \\
& +h\left(I-\frac{1}{b}\right)\left(\frac{b}{h\left(I^{\sigma}+I b\right)}\right)=0 .
\end{aligned}
$$

From this we can calculate

$$
\frac{d I}{d b}=-\frac{\frac{d X}{d b}}{\frac{d X}{d I}}
$$


where

$$
\begin{aligned}
\frac{d X}{d I}= & -\frac{1}{I}+h\left(\ln \left(1-\frac{b}{h\left(I^{\sigma}+I b\right)}\right)\right)+\left(h\left(I-\frac{1}{b}\right)-\frac{1}{\beta}\right) \frac{\frac{b\left(I^{\sigma-1} \sigma+b\right)}{h\left(I^{\sigma}+I b\right)^{2}}}{\left(1-\frac{b}{h\left(I^{\sigma}+I b\right)}\right)} \\
& +h\left(\frac{b}{h\left(I^{\sigma}+I b\right)}\right)-h\left(I-\frac{1}{b}\right) \frac{b\left(I^{\sigma-1} \sigma+b\right)}{h\left(I^{\sigma}+I b\right)^{2}} \\
= & h m-\frac{1}{I}-h(-\ln (1-m))-\left(\frac{m}{1-m}\left(\frac{1}{\beta}-h m\left(I-\frac{1}{b}\right)\right)\right) \frac{\left(I^{\sigma-1} \sigma+b\right)}{I\left(I^{\sigma-1}+b\right)} \\
= & -\frac{1-e_{s}}{I}-h(-\ln (1-m))-\left(\frac{m}{1-m}\left(\frac{1}{\beta}-\left(e_{s}-e_{n}\right)\right)\right) \frac{\left(I^{\sigma-1} \sigma+b\right)}{I\left(I^{\sigma-1}+b\right)}<0
\end{aligned}
$$

and

$$
\begin{aligned}
\frac{d X}{d b}= & \frac{h}{b^{2}}\left(\ln \left(1-\frac{b}{h\left(I^{\sigma}+I b\right)}\right)\right)-\left(h\left(I-\frac{1}{b}\right)-\frac{1}{\beta}\right) \frac{\frac{I^{\sigma}}{h\left(I^{\sigma}+I b\right)^{2}}}{1-\frac{b}{h\left(I^{\sigma}+I b\right)}} \\
& +\frac{h}{b^{2}}\left(\frac{b}{h\left(I^{\sigma}+I b\right)}\right)+h\left(I-\frac{1}{b}\right) \frac{I^{\sigma}}{h\left(I^{\sigma}+I b\right)^{2}} \\
= & \frac{h}{b^{2}}(\ln (1-m))+\frac{h}{b^{2}} m+\frac{1}{1-m} \frac{m}{b}\left(\frac{1}{\beta}-\left(e_{s}-e_{n}\right)\right) \frac{I^{\sigma}}{I^{\sigma}+I b} \\
= & \frac{h}{b^{2}(1-m)}\left((1-m) \ln (1-m)+m+m^{2}\left(\frac{1}{\beta}-\left(e_{s}-e_{n}\right)\right) I^{\sigma}\right)> \\
= & \frac{h}{b^{2}(1-m)}((1-m) \ln (1-m)+m)>0 \forall m>0
\end{aligned}
$$

To see the latter, note that

$$
\lim _{m \rightarrow 0}((1-m) \ln (1-m)+m)=0
$$

and

$$
\frac{d((1-m) \ln (1-m)+m)}{d m}=-\ln (1-m)>0 .
$$

Appendix 2: Unknown inaptitude

In the benchmark model we assume that inaptitude of a child is already known when education decision is made. In this appendix we explore the possibility that inaptitude is unknown at the time of this decision. While the main results of the paper still hold, one important new issue emerges. Under missing information parents and children bargain over the amount of investment in education, and it therefore depends on their relative bargaining strengths. This opens a discussion on the effect of differences in social and cultural norms on inequality and mobility.

Assume that the amount of education is decided before inaptitude is known. When education begins, the child immediately observes whether she can finish school or not, namely whether $e$ is below or above the amount of education purchased. If she can, she remains in school, and if not she leaves school and the parents get their money back. Note that under these informational assumptions, the offspring can bargain with the parent on the size of 
investment in education, threatening not to go to school if the amount is not high enough. The underlying conflict reflects the different interests of parents and children. While the latter always want to have more education, to raise probability of success, parents share this desire, but also care about own consumption. This conflict of interests is resolved in bargaining. We assume that parent and offspring use a simple form of asymmetric Nash bargaining.

The expected utility of parents at time of bargaining is:

$$
\ln w_{j}+\beta V_{n}+e_{j}\left[\ln \left(1-m_{j}\right)+\beta\left(V_{s}-V_{n}\right)\right]
$$

where $j=s$ if skilled and $n$ if unskilled. The threshold levels are: $e_{s}=m_{s} I h$ and $e_{n}=$ $m_{n} h / b$.

The expected utility of children to parents of type $j$ is:

$$
V_{n}+e_{j}\left(V_{s}-V_{n}\right)
$$

The threat points are $\ln w_{j}+\beta V_{n}$ and $V_{n}$ for parent and child respectively, and if the relative bargaining power of parents is denoted by $q$, the logarithm of the asymmetric Nash-product is

$$
\ln e_{j}+q \ln \left[\ln \left(1-m_{j}\right)+\beta\left(V_{s}-V_{n}\right)\right]+(1-q) \ln \left(V_{s}-V_{n}\right) .
$$

Substituting the threshold levels and maximizing yields that skilled and unskilled spend the same share of income $m$ on education, which is determined by:

$$
\beta\left(V_{s}-V_{n}\right)+q \frac{m}{1-m}-\ln (1-m) .
$$

We see that a higher bargaining power to parents $q$, reduces the share of income that goes to education $m$. While (A.2) is the new incentive curve in this extension, the gains curve is the same as in the benchmark model. Calculating the two relations together yields the function $m$

$$
\begin{array}{r}
-\frac{\ln (1-m)}{\beta}+\frac{q m}{1-m}\left[\frac{1}{\beta}-h\left(I-\frac{1}{b}\right) m\right] \\
=\ln (I)+h\left(I-\frac{1}{b}\right)[-\ln (1-m)-m] .
\end{array}
$$

Note that (12) is similar to the equilibrium condition (8), except for the element that depends on $q$. The other equilibrium conditions are derived as in the benchmark model. Clearly, the main results of the paper remain intact. The only novelty here is the new variable $q$, the bargaining power of parents. As the LHS of (12) increases with $q$, it leads to a downward shift of $m$ and of the $M$ curve, while the $L$ curve remains unchanged. Intuitively, when parents have more bargaining power over their children, they consume more and pay less for their education. Hence, upward mobility decreases and inequality increases. Thus, the social power of parents within the family can be another potential explanation for high inequality and low mobility.

\section{References}

Aghion, P., \& Bolton, P. (1997). A theory of trickle-down growth and development. The Review of Economic Studies, 64(2), 151-172.

Alesina, A., Glaeser, E., \& Sacerdote, B. (2005). Work and leisure in the U.S. and Europe: Why so different? NBER Macroeconomics Annual, 20, 1-64. 
Alesina, A., \& Rodrik, D. (1994). Distributive politics and economic growth. The Quarterly Journal of Economics, 109(2), 465-490.

Baland, J. M., \& Robinson, J. A. (2000). Is child labor inefficient? Journal of Political Economy, 108(4), 663-679.

Banerjee, A. V., \& Newman, A. F. (1993). Occupational choice and the process of development. Journal of Political Economy, 101(2), 274-298.

Barro, R. J. (2000). Inequality and growth in a panel of countries. Journal of Economic Growth, 5(1), 5-32.

Benabou, R. (2001). Social mobility and the demand for redistribution: The poum hypothesis. The Quarterly Journal of Economics, 116(2), 447-487.

Benabou, R. (2002). Tax and education policy in a heterogeneous-agent economy: What levels of redistribution maximize growth and efficiency? Econometrica, 70(2), 481-517.

Björklund, A., Eriksson, T., Jantti, M., Raaum, O., \& Osterbacka, E. (2002). Brother correlations in earnings in Demark, Finland, Norway and Sweden compared to the United States. Journal of Population Economics, 15(4), 757-772.

Blanchard, O. J., \& Wolfers, J. (2000). The role of shocks and institutions in the rise of european unemployment: The aggregate evidence. Economic Journal 110, 1-33.

Blanden, J., Gregg, P., \& Machin, S. (2005). Intergenerational mobility in Europe and North America-a report for the Sutton Trust. Centre for Economic Performance, London School of Economics.

Blau, F., \& Kahn, L. M. (1996). International differences in male wage inequality: Institutions and market forces. Journal of Political Economy, 104(4), 791-837.

Blau, F., \& Kahn, L. (2002). At home and abroad: U.S. labor markets in international perspective. New York, NY: Russell Sage.

Checchi, D., Ichino, A., \& Rustichini, A. (1999). More equal but less mobile? Education financing and intergenerational mobility in Italy and in the US. Journal of Public Economics, 74(3), 351-393.

Comi, S. (2003). Intergenerational mobility in Europe: Evidence from ECHP. Mimeo, Univerista degli studi di Milano.

Cooper, S., Durlauf, S. N., \& Johnson, P. A. (1993). On the evolution of economic status across generations. American Statistical Association Proceedings of Business and Economics, 83, 50-58.

Dahan, M., \& Gaviria, A. (2001). Sibling correlations and intergenerational mobility in Latin America. Economic Development \& Cultural Change, 49(3), 537-554.

Doepke, M., \& Zilibotti, F. (2005). The macroeconomics of child labor regulation. American Economic Review, 95, 1492-1524.

Durlauf, S. N. (1996). A theory of persistent income inequality. Journal of Economic Growth, 1(1), 75-93.

Erikson, C. L., Ichino, A. (1994). Wage differentials in Italy: Market forces, institutions, and inflation. NBER Working Paper No. 4922, 1994.

Fender, J., \& Wang, P. (2003). Educational policy in a credit constrained economy with skill heterogeneity. International Economic Review, 44, 939-964.

Fernandez, R., \& Rogerson, R. (1995). On the political economy of education subsidies. Review of Economic Studies, 62(2), 249-262.

Fernandez, R., \& Rogerson, R. (1998). Public education and income distribution: A dynamic quantitative evaluation of education-finance reform. American Economic Review, 88(4), 813-833.

Galor, O., \& Zeira, J. (1993). Income distribution and macroeconomics. The Review of Economic Studies, $60(1), 35-52$.

Galor, O., \& Tsiddon, D. (1997). Technological progress, mobility, and economic growth. American Economic Review, 87, 363-382.

Glomm, G., \& Ravikumar, B. (1992). Public versus private investment in human capital, endogenous growth and income inequality. Journal of Political Economy, 100(4), 813-834.

Güell, M., Rodríguez Mora, J. V., \& Telmer, C. (2007). Intergenerational mobility and the informative content of surnames. CEPR DP 6316.

Hassler, J., \& Rodríguez Mora, J. V. (2000). Intelligence, social mobility, and growth. American Economic Review, 90(4), 888-908.

Hornstein, A., \& Krusell, P. (2003). Implications of the capital-embodiment revolution for directed R\&D and wage inequality. Federal Reserve Bank of Richmond Economic Quarterly, 89(4), 25-50.

Lambert, P., Prandy, K., \& Bottero, W. (2007). By slow degrees: Two centuries of social reproduction and mobility in britain. Sociological Research Online, 12(1).

Loury, G. C. (1981). Intergenerational transfers and the distribution of earnings. Econometrica, 49(4), 843867.

Maoz, Y. D., \& Moav, O. (1999). Intergenerational mobility and the process of development. Economic Journal, 109(458), 677-697. 
Mayer, S. E., \& Lopoo, L. M. (2001). Has the intergenerational transmission of economic status changed? Mimeo.

Mourre, G. (2005). Wage compression and employment in Europe: First evidence from the structure of earnings survey 2002. Economic Papers no. 232, September 2005, European Commission, Directorate-General for Economic and Financial Affairs.

Owen, A. L., \& Weil, D. N. (1998). Intergenerational earnings mobility, inequality and growth. Journal of Monetary Economics, 41(1), 71-104.

Perotti, R. (1996). Growth, income distribution, and democracy: What the data say. Journal of Economic Growth, 1(2), 149-187.

Persson, T., \& Tabellini, G. Is inequality harmful for growth? American Economic Review, 84(3), 600-621.

Ryan, P. (2001). The school-to-work transition: A cross-national perspective. Journal of Economic Literature, 39(1), 34-92.

Solon, G. (1999). Intergenerational mobility in the labor market. Handbook of Labor Economics (Vol. 3A). In O. Ashenfelter \& D. Card (Eds.), Handbooks in economics (Vol. 5, pp. 1761-1800). Amsterdam; New York and Oxford: Elsevier Science, North-Holland.

Solon, G. (2004). A model of intergenerational mobility variation over time and place. In Corak, M. (Ed.), Generational income mobility in North America and Europe. Cambridge: Cambridge University Press. 